DOE/CS/40178.000-01

Volume 1 (of 2 Volumes)

\title{
Relevance of the Second Law of Thermodynamics to Energy Conservation
}

January 1980

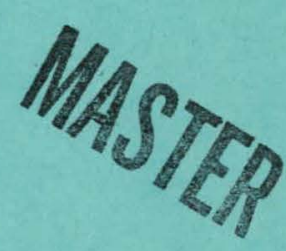

Prepared for:

U.S. Department of Energy

Assistant Secretary for

Conservation and Solar Energy

Office of Industrial Programs

Purchase Request No 01-79 CS40178.000 


\section{DISCLAIMER}

This report was prepared as an account of work sponsored by an agency of the United States Government. Neither the United States Government nor any agency Thereof, nor any of their employees, makes any warranty, express or implied, or assumes any legal liability or responsibility for the accuracy, completeness, or usefulness of any information, apparatus, product, or process disclosed, or represents that its use would not infringe privately owned rights. Reference herein to any specific commercial product, process, or service by trade name, trademark, manufacturer, or otherwise does not necessarily constitute or imply its endorsement, recommendation, or favoring by the United States Government or any agency thereof. The views and opinions of authors expressed herein do not necessarily state or reflect those of the United States Government or any agency thereof. 


\section{DISCLAIMER}

Portions of this document may be illegible in electronic image products. Images are produced from the best available original document. 


\section{Available from:}

National Technical Information Service (NTIS) II.S. Department of Commerce 5285 Port Royal Road Springfield, Virginia 22161

Price: Printed Copy: Micrufiche:

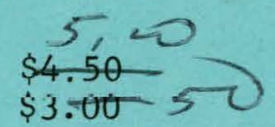


DOE/CS/40178.000-01

Volume 1 (of 2 Volumes)

Distribution Category UC95f

\section{Relevance of the Second Law of Thermodynamics to Energy Conservation}

January 1980

Prepared by:

National Bureau of Standards

General Energy Associates Inc.

Cherry Hill New Jersey

Purchase Request No 01-79CS40178.000

Prepared for:

o

U.S. Department of Energy

Assistant Secretary for

Conservation and Solar Energy

Office of Industrial Programs

Washington, DC 20545

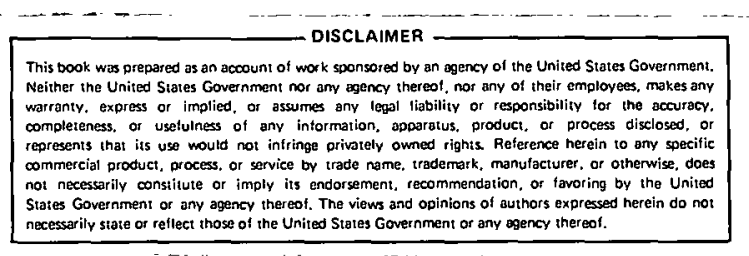




\section{Table of contents}

Page

I. Introduction

II. Background

A. Technical

B. Energy Conservation Programs

III. Methodology

IV. Relevance of Second Law Analysis to Energy Conservation Programs

v. Conclusions

References 


\section{INIRODUCTION}

Section 683 of the National Energy Conservation Policy Act (NECPA), Pub. L. 95-619, directs the Secretary of Energy to conduct a study (hereinafter referred to as the "study") of the "relevance to energy conservation programs of the use of the cancept of energy efficiency as being the ratio of the minimm available work necessary for accomplishing a given task to the available work in the actual fuel used to acoamplish that task". Section 683 specifies the programs to be covered by the study and requires the submission of a report on the study to the Congress. Part II of this report contains the study and Part I summarizes certain of its findings and applies them more specifically to statutory programs. The study was conducted by the Department of Energy in consultation with the National Bureau of Standards and under contract with General Energy Associates, Inc. (Contract NB79SBCA0166).

The concept of energy efficiency as stated in NECPA is based on the Second Law of Thermodynamics (Second Law). The laws of thermodynamics, as are all laws of physics, are generalizations based on observations. They are valid because they predict results which are in agreement with experiment. The First and Second Laws of thermodynamics cannot be described with precision in a non-mathematical manner. The essence of the First Law can be considered, however, as a statement that energy is conserved, i.e., the amount of energy put into a system equals the amount that can be withdrawn from the system. This allows an energy balance to be calculated for any system. 
Similarly, while there is no single, standard definition of the Second Law, it has been stated, in-part, as follows: it is impossible to produce a transformation the only effect of which is the extraction of heat from a heat reservoir and the performance of an equivalent amount of work. Since heat and work are two foums of energy, this means that there will always be losses (unavailable energy) in heat driven processes. Same heat will necessarily be wasted. These are unavoidable losses in addition to, and often larger than, the practical losses resulting from such things as friction and heat leaks.

The Second Law is an analytical tool which can address not only the quantity of energy flowing through a process but also its quality (capacity for doing workl and, more importantly, changes in quality. In terms of the Second Law, energy exists in different grades or qualities. For example, electrical or mechanical energy is of high quality while heat energy is of low quality.?

This concept is not new. It had its beginnings as early as 1803 with the works of L. Carnot on the reversibility of processes and the Idea thät reversibility is required for maximum work by a system. The concepts of reversibility and of entropy generation by irreversible . processes are central to an inderstanding of tho relevance of the sscrmd, Law to energy conservation. These concepts and the related concepts of availability (avallable energy) and lost work are addressed in the next section of this part.

Any material in which temperature, pressure, potential energy or concentration differs from that of the atmosphere, can produce work. The maximum amount of work can be produced through reversible processes. 
This is an ideal which cannot be achieved but which can be quantified using the Second Law and, hence, can serve as a reference level with which to compare actual performance.

Energy conservation can be viewed then as the reduction of (1) losses to the environment, and (2) degradations of high grade energy by inefficient processes.

One example of inefficiency is the use of high grade fuel for low temperature heat. It should be intuitively obvious, for example, that a $3000^{\circ} \mathrm{F}$ flame is not needed to heat water or air for residential purposes. This same example can be used to indicate how the pervasiveness and intuitiveness of same aspects of the Second Law further camplicate the determination of its relevanoe to various programs. The Second Law efficiency of residential space heating has been calculated to be approximately 7 percent as compared to a First Law efficiency of, say, 60 percent. The difference, of course, results from the consideration of the qualities of the energy provided and the energy required. In this example the determination of the relevance of Second Law dictates that certain questions be answered including the following:

- Will a jeirsun be bétter equipped to improve the efficiency of a furnace by knowing that its Second Law efficiency is 7 percent than by knowing that its First Law efficiency is 60 percent?

- Similarly, is the realization that the second Law efficiency of a particular item of existing equipment can be increased from 7 percent to 9 percent, more beneficial than the realization that the same actions will raise its First Law 
efficiency fram 60 percent to 80 percent?

- Will the quantitative data on the disparity between the availability of the fuel and the availability required by the heating tasks be more useful than the intuitive knowledge or observation that a substantial amount of availability is being lost in the form of waste heat?

- If samc boncfits can be associated with the explicit use of the second Law, arc thcy sufficient to justify the additional costs, if any, of using the alternative techinique?

These are examples of the types of questions which must be answered in order to determine the relevance of second Law analyses to any program.

The answers to these questions are necessarily subjective, in part, since many of the programs are still evolving and, even for well-defined programs, quantitative benefit/oost analyses would be required on a case-by-case basis.

The methodology used for this study is described further in section III of this part. The results of the application of the methodology to the energy conservation programs identified in section 683 of NECPA are presented in section IV of this part. Section V presents the conclusions reached by this study.

\section{BACKGROUND}

\section{A. TECHNICAL}

This section defines several terms used throughout the report and describes the thermodynamic basis for methods of determining the efficiency of practical processes. Energy, analysis is explained in some detail, together with same of its implications and limitations. . 


\section{Fundamentals}

The fundamentals of this study are:

Energy exists in many forms: chemical, electrical, mechanical (work), gravitational, magnetic and thermal (heat), etc. The equivalence of these forms of energy is specified by the First Iaw of Thermodynamics. The sources of energy include, for example, heat released during the combustion of fossil fuels and biamass, heat released by nuclear reactions, work or heat from falling water or from wind, and heat from solar radiation. Energy conservation, as the term is used in this study, has as its goal the efficient use of sources of energy.

Entropy is a property, common to all systems and related to energy, that specifies the feasibility of a process. The change in entropy is a measure of the ultimate limitations on the efficiency of conversion of other forms of energy to work in any process. Entropy is defined by the second Law of Thermodynamics. In order to calculate the useful work that can be done in a process, both energy and entropy changes must be considered. Broadly speaking, this is the principle that lies behind engineering applications of the Second Law.

Available Energy is that part of the total energy which can ideally be converted to useful work. In every-prooess-using heat energy there are inherent losses which cannot be overcame. 
Energy analysis treats the flow of energy, or the flow of energy along with the change of entropy, in a prócess. It is the study of efficiency and is a major tool in energy conservation studies.

Energy analysis is carried out on several levels of complexity in engineering practice and is used at various stages of operation in industry. Typical complexity levels are:

(a) energy accounting based on the First. Iaw of Thermodynamics,

(b) Eirst Law morgy accounting supplemented with a qualitative, intuitive application of the second Law,

(c) quantitative analysis of the availability (potential work) based on a combination of the principles of the First and Second Laws of Thermodymamics,

(d) analysis of the dymamics of a system, combining principles of: equilibrium thermodynamics, irreversible thermodynamics, physical and chemical kinetics and fluid mechanics;

(e) any or all of the above, combined with other technical conslaerations (e.g. reliability, safety, etc.), econanic analysis and consideration of social impacts.

Energy analyses may typically be applied at the following stages of an energy system's life:

(a) research and development on a new concept, 
(b) selection among different conceptual methods for performing a task,

(c) design of an operating system to perform a specific task,

(d) optimization of new or existing equipment - usually applied to special components,

(e) monitoring of system performance, and

(f) reporting of energy utilization.

All of these stages are of interest when methods of energy analysis are being compared; but the value of a specific analysis method may vary among different stages as well as among different systems.

A brief discussion is given below of the principles upon which thermodynamic energy analysis rests. These are the First and second Laws of Thermodynamics. Both of these laws are summaries of experience, backed up by over a century of experimentation. Thermodynamics is a rigorous mathematical science. What is presented below is qualitative.

The First Law states "that energy can neither be created nor destroyed" in a process but is converted from one form to another. The energy in a system and its surroundings is a constant. The internal energy of a system may change when it absorbs heat from or does work on the surroundings, but equivalent and opposite changes occur in the surroundings. If the internal energy does not change, then the output energy is equal to the input. From this principle it follows that simple energy accounting can be applied to prucesses as follows: the total energy in a system after a procese is equal to that present before the process occurred. The processes of most interest are those in which 
energy fram a fuel enters a system in one form and is converted to another form that is more useful to a particular task. For example, in a coalfired power plant, part of the energy released in the combustion of coal is converted to mechanical work (which drives an electrical generator) and the rest becomes "waste" heat.

The energy efficiency, $n$, of a process is the ratio of the output energy in the desired form to the energy applied to do the task:

$$
\mathrm{n}=\frac{\text { Euergy in thu desirat mitputs }}{\text { Energy applied to do the task }}
$$

For the power plant, electricity is the desired output. The efficiency could be stated as the energy in the electricity produced divided by the fuel energy of the coal.

Other measures of performance are often used: miles driven per gallon of gasoline consumed or pounds of aluminum produced per kilowatt hour of electricity used. The connection between these cormonly used measures and energy efficiency as defined above is often tenuous. However, they orc convenient and often more useful when similar systems or processes are being compared.

The Second Law of Thermodynamics introduces and quantifies anothur set of concepts. No single, precise, non-mathematical, easily understood statement of the second Law can he made. Three important (overlapping) concepts are:

- In a natural process randamess, or disorder, inucreases. Solids dissolve, liquids mix, gases expand to fill the available volume.

- In a natural, or spontaneous, process energy tends to flow fram a state of higher potential to ane of lower potential. Water 
falls under a gravitational potential, electrical charge flows to ground potential, chemical reactions run to equilibrum (not necessarily to completion), and heat flows from a body at a higher temperature to one at a lower temperature.

- It is impossible to construct a machine, operating in cycles, which will produce no effect other than the absorption of heat fram a reservoir and the conversion of that heat to an equivalent arrount of work. In practice this means that only a fraction of the heat absorbed at high temperature by the working fluid in a heat engine (turbine or piston engine) can be converted to useful work. Some of the input energy must necessarily be rejected into a lower temperature reservoir, (e.g. the atmosphere).

These concepts are quantified by the property entropy, as previously explained. An increase in entropy is a direct measure of an increase in randamess, or disorder, and of the portion of the energy that cannot be converted to useful work in the process.

The efficiency based on these concepts, often called effectiveness to distinguish it fram that based solely on the First Law, compares the theoretical least work-required to accamplish a task to the maximum work that could be derived (available work) from the actual fuel used to accomplish that task.*

* This definition differs frm some textbook definitions for calculating the maximum energy efficiency of a heat engine. The latter is process oriented. The present definition is more general. It is task oriented and makes no reference to the actual operating conditions of the process. Instead it considers what could be done in an ideal, limiting case, , possibly using an extremely different technology. 


$$
E=\frac{\text { Minimm work required to do the task }}{\text { Potential work avialable in the inputs }}
$$

The effectiveness for a process often is appreciably less than the efficiency. Although somewhat more complex to calculate than efficiency, effectiveness often is a better measure of the opportunity for improvement. Because effectiveness campares the achieved with the achieveable it has been recommended as a rational approach to measuring the utilization of energy sources.

Most energy analyses conducted today are done on a First Law basis with a qualitative awarcness of the second Iaw concepts. This awareness means that it is understood that both the energy quantity and quality (potential level) are important. For installe, in ordcr to achieve high second Law efficiency ane should match the temperature of the energy source to that of the operating system as closely as possible. Also, one should arrange that the inevitable heat rejection fram the system should be done at a temperature applicable to the design (or redesign) phase of an industrial proccss. For srme cases both First and second Taw, methods give substantially the same result. This must be determined by detailed analyses of typical processes. When this is the case, simplicity is to be preferred. Buth methode can be used to assess the needs for developing new processes or to seltul among possibilities. The second Law approach provides a better comparison in this application. At least a conceptual appreciation of the Second Law is essential for all concernod with the general planning stage of industrial systems.

When applying any of the energy analysis techniques, it is imperative that the system be well defined and the appropriate thermodynamic properties 
of the inputs and outputs be known. For application of the First Law analysis, this means that the thermodymamic property; energy content, must be known for the fuels, feedstocks and products. For the second Iaw application, another property, entropy, must be known. This property is more difficult to obtain. There are larger gaps in the data bank for this property than for energy. This is not a limitation for the most significant industrial case, the generation and use of steam, simply because an immense amount of careful work has been done to establish the properties of steam. "There is also a large body of data for metallurgical systems. However, for many chemicals neither of these properties is known and for others the energy content is known but the entropy is not. Where these essential properties are not known, the technique can not be applied.

Energy analysis, based on first law only, may usually be used for comparing the relative performances of similar systems that are producing an identical product or energy output. The performances of different systems, which are producing different products, are more difficult to campare. Usually a second law analysis of some form must be incorporated with first law analygia so as to establigh a maximm performance limit. It is then possible to campare the respective ratios of theoretical to actual performance for each system and determine which is closer to ideal perfomance. However, comparing the performance of one system, with that of another using this indicator alone can be very misleading since factors other than energy analysis must also be cansidered." Improving the performance of a system may be impractical for various technical reasons: strength 
of materials, requirements for high rates of production, inability to control combustion temperatures, corrosion, pollution, etc. In addition, energy performance is often subordinate to economic and other considerations.

In spite of these difficulties, availability analysis remains important. It is availability (potential energy), not energy, for which we pay. Availability is consumed in the cambustion of a fuel, not energy. Therefore, everywhere that availability is destroyed in a system, there is a corresponding penalty. The decrease in availability is a measure of what that particular inefficiency costs the operator of the system. An important use of availability analysis techniques has been in the quantification of life cycle costs for a system (capital and operating costs). Attempts to formalize this application, by incorporating optimization techniques, are presently under development. This combined analysis of the availability of an energy system and its cost (in dollars) may well prove to be the most valuable contribution of the Second Law techniques.

\section{B. ENERGY CONSERVATION PROGRAMS}

The purpose of this section is to describe the energy conservation programs covered by this study and to note the aspents of each mmgram for which the concept of energy efficiency deriving from the second law of thermodynamics may be relevant. Section 683 of NECPA required specifically that the following energy conservation programs be covered:

1. Those authorized in ...

a. The Energy Policy and Conservation Act (EPCA), Pub. L. 94163 as amended by Pub. L. 94-385 and Pub. L. 95-619:

b. The Energy Conservation and Production Act (ECPA), Pub. I. 94-385, as amended by Pub. L. 95-617 and Pub. L. 95-619; 
c. The National Energy Conservation Policy Act (NECPA); and

2. Appropriate Federal programs in enerğy research, developinent and demonstration. (Principal authority in this area is Pub. I. 93-577, the Federal Nonnuclear Energy Research and and Development Act.)

In general; all of these programs fall under the responsibility of the Assistant Secretary for Conservation and Solar Energy, with important related roles played by other offices in DOE, other govermment agencies including State and local governments, and private sector organizations.

Many of the programs authorized by the above statutes are concerned with related aspects of the same technologies within the various sectors of the energy economy. Therefore, in the analysis (Section IV), the principal technologies associated with each sector are discussed rather than the individual programs. For example, in the area of building energy conservation, the technologies of applicances; building heating, ventilating and air conditioning systems; and total energy or oogeneration are considered rather than each of the numerous specific programs described below.

The general topic of solar energy is not explicitly addressed in this study although it does arise in a number of these statutes. Solar is not usually considered as an_energy conservation-technology. Moreover, there is no concensus on the reference temperature to use in applying Second Law techniques to solar systems.

The following is a summary of certain Federal energy conservation programs grouped according to major energy-using sectors of the econamy (building, industry, transportation, and utilities). 


\section{Energy Conservation in Buildings}

Programs and technologies aimed at improving efficiency of energy use in new and existing buildings and associated appliances and equipment offer important contributions to the total national energy conservation effort. Legislated programs in this area include the following:

- Energy Conservation Standards for New Buildings (Pub. L. 94385, sections 301-311). This program involves the development and implementation. "as soon as practicable of performance standards for new residential and commercial buildings which are designed to achieve the maximm practicable improvements in energy efficiency and increases in the use of nondepletable sources of energy". DOE's proposed standards were issued for public camment on November 14; 1979 (44 FR 68120, November 28, 1979). The standards will require new buildings to meet specific design energy budget levels. Because they are performance rather than component standards, designers and builders will retain flexibility in choosing designs which achieve significant energy savings. In developing these standards, DOE is carrying out extensive research and technology development efforts which will signiflcantly advarwe the state-of-theart for the energy efficient design of the new buildings.

- State Energy Conservation Plans (Pub. L, 94-163, section 361366; Pub. L. 94-385, section 431-432; Pub. L. 95-619, section 621-623). This program sets forth the requirements that State energy conservation plans must meet to be eligible for 
Federal assistance. They include mandatory lighting efficiency standards for public buildings, mandatory standards and policies relating to energy efficiency in procurement practices, and mandatory thermal efficiency standards and insulation requirements for new and renovated buildings.

- Weatherization Assistance for Low-Inoome Persons/Families (Pub. L. 94-385 sections 411-422; Pub. L. 95-619, sections 231-233). The purpose of this program is to develop and implement a weatherization assistance program to aid in achieving the prescribed level of insulation in dwellings of low-incame persons. This is a financial assistance program. DOE's regulations for this program are required "to achieve a balance of a healthy dwelling environment and maximum practicable energy conservation".

- Residential Conservation Service Program (Pub. L. 95-619, sections 210-225, 10 CFR Part 456 (1979)). This program requires large electric and gas utilities and, on a voluntary basis, oil dealers to inform custamers, of suggested energy conservation and renewable resource measures and to provide estimates-of the-energy savings and-costs-for-such measures. The principal technical issues include identifying the appropriate standards necessary for safe and effective installation of the program measures, and determining which measures are appropriate for use in a given location and category of building. 
- Energy Conservation in Schools and Hospitals (Pub. L. 95-619, sections 301-312). This program involves grants "to states and to public non-profit schools and hospitals to assist them in identifying and implementing energy conservation maintenance and operating procedures and in evaluating, acquiring, and installing energy conservation measures to reduce the energy use and anticipated energy costs of schools and hospitals". As with the Residential Conservation Service Program, this program involves explicitly defined energy conservation measures.

- Energy Conservation and Measurement in Federal Buildings (Pub. L. 94-163, section 318, Pub. L. 95-619, section 501-551). These programs involve efforts to improve efficiency of energy use. in new and existing Federal buildings and facilities and to encourage renewable resource systems in such buildings and facilities.' In particular, it is the purpose of these programs to promote the use of commonly accepted methods to establish and campare the life-cycle costs of operating Federal buildings and the life-cycle fuel and energy requirements of such buildings, with and without special features for energy conservation and ". . the use of solar heating and cooling and other renewable energy sources in Federal buildings."

- Appliance Labeling and Minimum Efficiency Standards (Pub. L. 94163 sections 321-339; Pub. I. 95-619, sections 421-427). This program is aimed at improving the efficiency of a variety of hame appliances such as refrigerators, dishwashers, clothes 
dryers, air conditioners, and home heating equipment. DOE has developed test methods which are presently being used for the energy efficiency labeling of appliances under regulations of the Federal Trade Commission.

\section{Industrial Energỳ Conservation}

The effect of increased fuel prices and altered patterns of fuel availability has stimulated many commercial and industrial fims to improve the efficiency with which they use energy. Mandated programs in this area include the following:

- Industrial Energy Conservation (Pub. L. 94-163, sections 371-376; Pub. L. 95-619, section 601). This program is designed to "promote increased energy efficiency by American industry." This program requires each corporation which consumes at least one trillion British Thermal Units of energy per year and is within one of the 20 major energy-consuming industries identified by DOE to report annually to DOE on the progress made by that corporation in improving its energy efficiency. Further, this program requires the Secretary to establish energy efficiency improvement targets for at least the 10 most energy-consumptive industries and to apprise the congress of the progress made toward meeting such targets.

- Industrial Equipment Energy Efficiency (Pub. L. 95-619, section 441). "The purpose of this part is to improve the efficiency of electric motors and pumps and certain other industrial equipment in order to conserve the energy resources of the Nation". 
The types of equipment covered include compressors, fans, blowers, air conditioning and refrigeration equipment, electrolytic and electric arc equipment, steam boilers, ovens, furnances, kilns, evaporators and dryers. This statute requires a study to determine the practicability of requiring electric motors and pumps to meet performance standards establishing minimum levels of energy efficiency. Further, it authorizes the secretary of Eneryy to conduct similar evaluations of other types of industrial equipment.

- Recovered Materials (Pub. L. 95-619, section 461). The purpose of this program is to conserve valuable energy and scarce natural resources by establishing targets for increased industrial utilization of recovered materials for four industries: metals and metals products; paper and allied products; textile mill products; and rubber. In establishing these voluntary targets, the technological and economic ability of each affected industry to progressively increase its use of energy-saving recovered materials must be considered. Each corporation in the four industries which reports under the Industrial Energy Conservation Program must also report annually to DOE an its progress

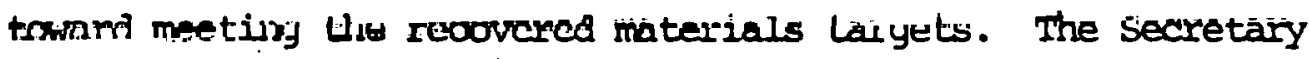
mast include a report on this program in his report to Congress on the Industrial Energy Conservation Program.

3. Transportation

Transportation accounts for approximately 25 peroent of energy in use. 
A major energy conservation program of interest in this study is:

- Automotive Fuel Economy (Pub. L. 94-163, section 301; Pub. I. 95-619, section 401-404). This statute requires the establishment of average fuel economy standards for automabiles. Average fuel econamy is defined in terms of a fleet-weighted average for all the vehicles produced by a manufacturer in a given model year. The standards range from an average fuel economy standard, in miles per gallon, of 18 in 1979 to 27.5 in 1985 and thereafter.

\section{Utilities}

Efficiency of energy use by Public Utilities particularly in electric power generation, is an important element of the national energy conservation effort. A major mandated program in this area is:

- Rate Design Initiatives for Electric Utilities (Pub. L. 94-385, section 204). The purpose of this program is to fund regulatory rate reform initiatives. In addition, under the Public Utility Regulatory Policies Act of 1978, Pub. L. 95-617, State regulatory bodies and nonregulated utilities are required to consider eleven ratemaking and regulatory policy standards with respect to, among other things, the conservation and efficient use nf. resourcee.

III. METHODOLOGY

Typically, the criterion use to establish the relevance of an analytical tool to application in a particular area is that its use is cost-effective relative to ollier avallable tools. This may mean that the tool in question provides the same information as other tools, but more quickly, with less effort or at a lower cost; or, it may mean that the tool in question provides 
new or additional information, the value of which is greater than the additional costs associated with its use. Therefore, the general criterion used in this study for assessing the relevance of second Law analyses to energy conservation programs can be stated as follows: the concept is relevant if it provides data, information, or insights of sufficient value, or other benefits beyond those obtained using "conventional" energy analysis techniques, in relation to its additional costs.

This general criterion is applied to the various energy conservation programs and generic classes of potential energy use.

In order to satisfy the general criterion, a number of determinations mast be made with regard to each conservation program considered in the study. First it must be determined whether the concept of energy efficiency, in any form, is relevant to the program. If it is not then no further consideration of the program is needed. If energy efficiency is a relevant consideration then it must be determined whether the use of Second Law analyses provides benefits, in addition to those provided by existing analytical practices. In making this determination the benefits to the various potential users or types of decision-makers (e.g. government officials, industry managers, consumers) must be considered. Some programs, such as appliance labeling, are intended primarily to provide energy efficiency information to consumers, and are evaluated accordingly. Other programs, such as FD\&D programs are intended to provide energy efficiency information to more than one distinct type of decision-maker. (e.g., industry and govermment) and the utility of Second Law analyses to each type must be evaluated. 
Finally, if any additional benefits of using second Law analyses are identified, it must be determined whether the benefits exceed the costs associated with them. Additional costs associated with the use of Second Law techniques may result fram such things as determining the additional thermodynamic properties of materials or aoquiring additional knowledge to implement the more complex analytical techniques.

Detailed quantitative estimates of the relative benefit/oost of using Second Law analyses were not made for each of the programs considered since they must be made on a case-by-case basis. The determination of relevance to conservation programs can, in most cases, be made in the absence of such detailed estimates by comparing the elements of each program to the numerous examples of successful application of Second Law techniques. This comparison was made by DOE in consultation with NBS. Experts in thermodynamics, energy conservation and related technical disciplines determined the relevance of Second Law anlyses to the subject.programs and formulated the rationales for those determinations. In each case one of three levels of relevance is determined; i.e., Second Law analysis is (1) relevant; (2) of limited applicability; or (3) not relevant in view of the general criteria discussed above. In cases of limited applicability, it is often possible to identify particular_elements of a program to-which-Second-Iawanalyses are relevant even though the concept does not enhance the total program. The results of those determinations are presented in the next section of the report.

IV. RELEVANCE OF SECOND IAW ANALYSIS TO ENERGY CONSERVATION PROGRAMS

. The methodology outlined in Section III was used to analyze the relevance 
to certain energy conservation programs of techniques based on the Second Law. This involved first identifying the energy technologies or systems pertinent to the various energy conservation programs identified in Section 683 of NECPA. The resulting list of technologies or systems follows:

- Household appliances;

- Building heating, ventilating and air conditioning systens;

- Total energy or cogeneration systems;

- The automobile;

.o Generation and use of process steam;

- Direct heating of materials in industrial manufacturing processes;

- Materials processing, including extractive, recovery, refining, chemical, reforming, and fabrication; and

- Generation of electric power.

The potential relevance of Second Law analysis to each of these technologies, in the context of the Fede'al energy conservation programs, was reviewed using the information set forth in Part II of this report and other relevant information as discussed below. The rationale for the potential rehevance of Second Law analyses to energy conservation programs is similar within each of the following functions: (1) planning and setting research priorities; (2) design, analysis, and testing of components or systems; and (3) monitoring or rating of operating systems; hence, the basis for the determination of relevance to operating systems is discussed in terms of each of these functions.

The determinations for each of these three headings represent judgments on the potential relevance of Second Law analyses to the general types of - 
Fedexal energy conservation programs indicated. There are many aspects of each of these energy conservation program areas for which second Law analysis is abviously of little or no direct benefit; for example, in developing State energy conservation plans or in developing innovative utility rates.

\section{Planning and Setting Research Priorities}

General planning and research priority-setting involve generalized analyses and decisions relating to choices of technologies, to conceptual approaches and to basic decisions affecting resource allocation. Formalized availability analyses appear to be most useful in this context. Part II of the report identifies a number of specific examples of appropriate and effective use of Second Law analyses in conceptual design of industrial processes. Also, the Office of Industrial Energy Conservation, DOE, has made use of Second Law analyses in establishing its research program priorities and in identifying areas of particular promise for potential. efficiency improvement in the most energy-intensive industries. Historically, Second Law analysis has found its most widespread use in the system conceptual design stage. Principal examples arise in the context of total. energy or cogeneration strategies which make effective use of the rather large-amounts-of heat that-are-rejected. Second-Iaw-analyses-are-also particularly useful in analyzing industrial heating or materials processing technologies for planning purposes. Chemical processing industries have utilized Second Law analyses in this context for many years.

Obviously, this is but one of a number of tools used in the planning stage but with increasing energy prices and with looming constraints on 
available supplies of energy, it is one that will increase in importance. One constraint on more widespread use of Second Law analyses in this context is the unavailability of needed data for various materials and for cammonly accepted definitions of reference states. Also, it should be obvious that all heat rejected in one process is not equally useful in others. In may industrial enterprises, particularly those involving canplex processes with many different energy systems, tools such as Second Law analysis are essential to achieving optimization of natural resource use.

Although Second Law analyses are somewhat less directly relevant to residential appliances and heating, ventilating and air conditioning systems, they are useful in identifying areas for potential improvement in these systems and for identifying possible combinations of traditionally independent functions that may be practicable. Current developments in heat pump technology and applications provide a good exarmle. Potentially beneficial technology cambinations include ground water heat pumps, hot water heater heat pumps, and heat recovery from refrigeration for water pre-heating:

Obviously, improved autamabile efficiency is an important national goal. Considerable Federal as well as industry effort is being directed toward identification of potentially more efficient forms of autamotive transport than provided by state-of-the-art internal combustion engines. However, economy in the use of fuels is just one of many factors of concern in personal transport system design. Thus, Second Law analysis is of limited usefulness in pimpointing targets of opportunity in various areas of autamotive research. 


\section{Design, malysis, and Testing of Components or Systens}

Assessments of the potential relevance of Second Law analysis to design analysis or testing of energy systens and their components range from useful to limited applicability for the technologies and programs considered.

These assessments are consistent with the examples in Part II of the report. The Second Law is most appropriate in the process and system design and modification area and for component design. Detailed examples of component design are presented in Part II which addresses heat exchangers, petroleum heaters, multi-effect evaporators, and distillation processes. Examples in the area of process design. include pulp mills (the Kraft process), processes for producing alkalies and chlorine, ethylene production, a number of petroleum refining processes, and primary aluminum production.

The implicit use of second Law concepts by engineers in process design and modification has been widespread in industry for years.

The potential relevance of application in the areas of buildings, mechanical systems, appliances, and automobiles is somewhat limited because of the often overriding importance of user requirements vis-a-vis energy efficiency in the design of such systems.

As with any analytical tool, the applicability of Second Law analysis is highly situation-specific. Thus, it is difficult to-generatize-and, indeed, it would be inappropriate to specify its use industry-wide. The potential benefits derivable from its application depend in a large part on the state of development and quality of the analytical or computerized models and basic data available to the system or component design engineer and, of course, the designer's ability to use these tools. 
Indeed, increased efforts on the part of the Federal Government to help industry produce needed data and models and to develop appropriate training materials may be most effective in stimulating more widespread use of this important analytical tool.

\section{Monitoring or Rating of Operating Systems}

The essential requirement in monitoring or rating of operating system performance is to characterize performance in useful terms. The principal use of such information is in tracking the overall performance of a program or in providing essential feedback on the operation or maintenance of an existing system or for use by designers. In the case of virtually every one of the energy conservation programs considered, currently used measures of the energy efficiency of operating systems are adequate, well-established, and widely used. Thus, for a measure of system operational performance based on the second Law to be of interest, it must provide relatively more useful or important new information. In general, this does not appear to be the case. It is generally inappropriate to use an availability measure to compare processes or systems whose products or end functions are different. Where the product or function is the same, present efficiency measures are quite adequate. Such measures include, for example, miles per gallon for autanobiles, energy efficiency ratio for appliances, measures such as Btu's per hour for HVAC systems, and Btu's per pound of product in a number of industrial processes. Twenty diverse industrial processes are reviewed in Part II to examine various availability measures. None of the measures were 
found to have any inherent advantage relative to others and none appear to provide any intrinsic insights when comparing different processes.

The only exceptions imvolve cases of total energy or cogeneration systems. In these cases, system output is partly thermal and partly mechanical, and second Law efficiency analysis is useful. (An example is presented in Section 3C of part II). Overall Second Law analyses may offer some marginal benefit in programs involving analyses of $\infty$ generation and similar energy systems.

A summary of the results of the analysis of the relevance to energy conservation programs of the Second Law of thermodynamics is presented in Table 1: Colum 1 of the Table lists the various groups of Federal energy conservation programs described in section IIB. The second colum of the table identifies potentially relevant existing energy technologies or systems considered in examining each of the major energy conservation program areas. Major technical systems or components not particularly affected by Second Law analysis are not shown. (For example, consider the area of building energy conservation. The thermal resistance of a building envelope and its design are largely functions of weather, indoor-outdoor temperature differentials, and materials properties. In this instance, second-Iaw-analysis-is-of little-relevance-since-it-provides-no-additional information. Similarly, in the transportation area, transportation network configuration, traffic generation and density distributions are affected by a wide range of socioeconomic as well as technical factors and are beyand the scope of Second. Law analysis techniques). 
potent:al Relevance CP SEcond lan to energt conservation prograys

(colum 1)

EnERCY CONSERVATION. PROCRAMS

(adenotes prograns involving

technologies in column 2)

Dulldinge Enersy Conservation:

"Energy conservation atandards

for ney bulldings.

- State energy conservetion plana

- Weatherleation asalatance

- Residential Conservation Service

- Energy conservation 6 renewable

resource denongtration

Energy conservation in schoolo

- hosptiala

- Energy conservation oolar energo

in Federal bulldings

Appliance labeling, effletency

improvement cargeto, 8 inimu

efficlency ctandards

Induatrlel Energy Conservat lon:

industrial reporting

Industrial equipment efflelency

arecovered materials

ARDSD programs

Transportation:

*Autonotive fuel econow

ARDSD prograns

\section{oellitiee:}

Race design Intelatives

aRDSD prograns
(Colum 2)

(Column 3)

EXTER: TO MHICH 2ND LAK ANALYSIS

MAY BE RELEVANT IN .

POTENTIALLY RELEVART

EXISTING ENERC:

TECHNOLOGIES OR STSTEMS

Heat ing, rentilation, \& itr

condit loning syotems

Appliances

Total ene:gy or cogeneration

Process izean

Direct heating of aterials Materisls processing

Automob1lea

Process aseas

Generation of electric power

Te.31Rn-Analya1s 8 Testing

$\triangle$

]

$\triangle$

$\triangle$
Reseurch rrioritles af Componentyysteinn

Mon1toring or Rating

O

$\square$

\begin{tabular}{|c|c} 
& \\
& $\Delta$ \\
$\Delta$ & $\Delta$ \\
\hline
\end{tabular}

KET, Second law analys 1o 1s...

$\triangle$ useful

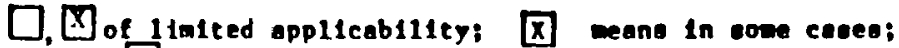

$\square$ meass of marginal benefit.

Onot beneffelal 
The third column of Table I presents the principal results of this study. This column contains three subcolumns representing the three generic situations for which the potential relevance of second Law analysis has been considered: general planning or establishing research priorities; as a tool for system or component design, analysis, evaluation, or testing; and, finally, in the monitoring and/or reporting of system operational performance.

The energy conservation programs involving technologies of potential interest are highlighted with an asterisk in Table 1. Since the Second Law is often not relevant to same parts of some programs, the determinations shown in the table relate only to those technologies such as the exarmles listed in column 2 for which it is appropriate to consider Second Law analysis.

V. OONCIUSIONS

This study has presented an analysis of the potential relevance of the use of analytical tools based on the second Law of thermodynamics to existing Federal energy conservation programs. It is believed to have addressed the most significant of potential applications and programs. This is a rapidly developing field with new applications contimually arising that could change in detail the assessment provided herein. However, it is not expected that foreseeable developments will alter substantially the major conclusions of this effort.

The principal conclusions of this study are the following: - Energy analysis techniques are commonly used in current engineering 
practice. Both First Law and Second Law analysis techniques are used.

- Second Iaw availability analysis is a useful tool, but only one of a number of directly pertinent planning and analysis tools.

- Second Law analyses provide useful information and insights about energy systems, i.e., where various energy losses of different types occur, but it does not determine what to do about such losses. The latter reguires additional insight.

- In any engineering analysis, the relative importance of any particular analytical tool varies considerably among different applications.

Application

Planning

- Second Law analysis is highly pertinent to planning and research priority setting and is already being used widely in this context.

- Second In analysis is very often appropriate for correiptual desigh and assessment of new ideas.

\section{Design:}

- Energy analysis is just ane of a muber of performance measures that can be used in designing or evaluating energy conservation programs.

- Second Law analysis can be useful in the detailed design of a system. The more camplex a system, the greater chance that it will be useful. 


\section{Monitoring:}

- In most cases, neither First nor seoond Iaw analyses are in themselves sufficient to establish practical limits. Other technical factors such as strength of materials, speeds of chemical reaction, needed rates of production, corrosion and pollution control must be considered.

- There is little or no advantage to using Second Law analyses as opposed to energy accounting in monitoring the performance of an existing plant or system.

- In most cases examined, including those involving intraindustry comparisons, existing monitoring and reporting measures appear adequate. Exceptions involve complex processes with many energy streams. Second Iaw analysis does not resolve difficulties in making inter-industry comparisons; for example, comparing the efficiency of aluminum with steelmaking processes.

Needs:

- The potential applicability of Second Iaw analysis to the long-term policy aspects of optimal resource allocation renains-to-be-established.

- Increased use of Second Iaw analysis, where appropriate, is contingent upon development of better data, models, and further generalized education and training.

- Appropriate intercomparisons require data for common reference states to be developed and defined. 
- Fundamental research and applications are needed to further develop Second Law-based analytical tools and computer models.

- An adequate data base needs to be established on thermodynamic properties of materials widely used in conmerce and industry.

- Specialized reference and course materials are required for education and training in many engineering disciplines.

In the final analysis, second Law analysis techniques must be viewed in the context of a broader range of engineering tools and along with economic, institutional, political, and social factors in making important decisions regarding energy conservation. For example, to reduce wasted availability in heat transfer processes requires reducing the temperature difference between the transfer streams. This in turn requires larger heat transfer equipment and/or longer process times. At some point, the required increases in equipment size or process time become infeasible. The optimal sizes and times depend on tradeoffs among energy costs and other costs. In real systems it is not possible to exchange heat with an infinitesimal temperature difference. Same loss in availabillty must be accepted as the price of achieving heat exchange in a finite time and with a finite heat exchange area.

The conclusions of this report establish no bașis for requiring Second Law efficiency analysis as a mandatory factor in controlling any 
particular facet of govermment or industrial activities in energy conservation. This report has pointed out, in a general way, the potential relevance of Second Law analyses. These are neither simple nor routinely used techniques. It is characteristic of the state-of-the-art of development of these tools that the relative benefit/cost of their use should be considered on a case-by-case basis.

*U.S. COVERNEMT PRIMTING OPPICE: 1980-0-620-309/2675 
United States

Department of Energy

Washington, DC 20585

Official Business

Penalty for Private Use, $\$ 300$ PENALTY FOR PRIVATE OF POSTAGE, $\$ 300$

DOE 350

THIRD CLASS MAIL 